\title{
STUDI SERANGAN RAYAP PADA TANAMAN AKASIA (Acacia crassicarpa) di lahan HTI PT MUARA SUNGAI LANDAK KABUPATEN MEMPAWAH
}

\author{
(Termite Attack Study on Acacia (Acacia crassicarpa) Plants in HTI land of PT Muara Sungai \\ Landak Mempawah Districts)
}

\author{
Fran Gino Libertus, Farah Diba \\ Fakultas Kehutanan Universitas Tanjungpura Jalan Daya Nasional Pontianak 78124 \\ E-mail: franmoreng@gmail.com
}

\begin{abstract}
Termites are small insects, similar to ants, found in many places, in forests, yards, gardens and even in the house. Termite nests are found in damp places in the soil and wet logs, but some live in dry wood. The main food is wood and materials from cellulose and fungi. The area of work is 13,000 hectares. The basis for the division of land carried out and land use planning PT. Muara Sungai Landak has 2,500 ha of land for planting Acacia Crassicarpa plants. This research was conducted in the RKT 16/17 HTI area of PT Muara Sungai Landak. The study used a field survey method, by laying the first plot using purposive sampling, laying the second plot and so on using systematic sampling. The termite sampling taken in this study was the termite soldier. Termite samples were put in a vial bottle containing 70\% alcohol. The analysis used two calculations, namely the calculation of the incidence of attacks and the intensity of the attacks. The results of the study of 46 plots with a total of 2944 trees, found 260 trees with mild attacks, 25 trees with moderate attacks, 9 with severe trees. The type of termite found was Nasutitermes longinasoides and Coptotermes sp. The incidence rate of termite attack occurred in all plots, namely 46 observation plots with the highest attack incidence rate of $21.31 \%$ and the highest intensity of attack $47.18 \%$.
\end{abstract}

Keyword: Acacia crassicarpa, Event of Attacks, Intensity of attack, PT Muara Sungai Landak, termites

\section{PENDAHULUAN}

Rayap adalah serangga kecil, mirip dengan semut, dijumpai di banyak tempat, di hutan, pekarangan, kebun, dan bahkan di dalam rumah. Sarang rayap terdapat di tempat lembab di dalam tanah dan batang kayu basah, tetapi ada juga yang hidup di dalam kayu kering. Makanan utamanya adalah kayu dan bahan-bahan dari selulosa serta jamur (Amir, 2003). Rayap menyerang tanaman Akasia di PT Muara Sungai Landak (MSL)

PT. Muara Sungai Landak adalah areal berdasarkan RKUPHHK-HTI keputusan Menteri Kehutanan No, SK.243/Menhut II/2012 tanggal 21 Mei 2012. Luas areal kerja adalah $13.000 \mathrm{Ha}$. Dasar pembagian wilayah yang dilakukan dan perencanaan penggunaan lahan PT. Muara Sungai Landak memiliki lahan untuk ditanami tanaman akasia adalah seluas 2.500 ha.

Tanaman akasia (Acacia sp) telah ditanam oleh lebih dari 80 negara di dunia termasuk Indonesia. Beberapa jenis tanaman akasia yang banyak ditanam di Indonesia adalah Acacia auriculiformia, 
Acacia mangium, Acacia crassicarpa dan Acacia aulacocarpa.

Tujuan dari penelitian adalah Mengetahui tingkat kejadian serangan rayap pada pohon Akasia di lahan HTI PT Muara Sungai Landak Kabupaten Mempawah dan Mengetahui tingkat intenstas serangan pada tanaman akasia akibat serangan rayap. Sedangkan mamfaat penelitian adalah sebagai informasi dalam pelaksanaan penanaman bibit akasia (Acasia crassicarpa) baik dalam HTI maupun di luar HTI untuk pencegahan dari serangan rayap dan sebagai data dasar untuk menentukan tindakan pengendalian serangan rayap terhadap Accasia crassicarpa berdasarkan tingkat serangannya.

\section{METODE PENELITIAN}

Penelitian dilaksanakan di areal HTI PT. Muara Sungai Landak, Wajok, Kabupaten Mempawah selama satu bulan di bulan Juni 2019. Alat penelitian menggunakan GPS, penjepit rayap, cangkul dan termometer. Sedangkan bahan penelitian menggunakan ATK, kertas label, alkohol $70 \%$, buku rayap dan kamera. Objek dari penelitian ini adalah tanaman Acasia Crassicarpa di areal RKT 16/17 dengan luasan 922 ha. Penelitian menggunakan survei lapangan dengan cara petak ganda dengan peletakan petak contoh secara purposive sampling Petak contoh dibuat dengan ukuran 20 x 20 meter. Petak pertama dilakukan secara purposive sampling, kemudian dilakukan secara sistematik sampling untuk petak berikutnya. Jarak antar petak adalah 20 meter dan menyesuaikan dengan kondisi di lapangan RKT 16/17. Data diambil dari lokasi penelitian berupa jumlah tanaman yang rusak dan tingkat kerusakan kejadian serangan dan intesitas serangan akibat serangan rayap dan gejala yang ditimbulkan. Tingkat kerusakan diklasifikasikan berdasarkan tipe kerusakan tanaman akibat serangan rayap.

Adapun skor kerusakan tanaman oleh serangan hama yang digunakan: disajikan pada Tabel 1.

Tabel 1. Nilai (skor) pada kondisi rusak terserangan rayap pada setiap pohon (Value in damaged conditions attacked by termites in each tree)

\begin{tabular}{lc}
\hline \multicolumn{1}{c}{ Kondisi Pohon } & Skor \\
\hline Tidak terserang tidak ada serangan rayap & 0 \\
Terserang ringan bagian pohon yang terserang relatif sempit ditandai dengan adanya & \\
kerak tanah pada batang pohon atau kerak tanah berupa alur-alur yang terdapat pada & 1 \\
perakaran dan batang & \\
Terserang sedang bagian pohon yang terserang relatif agak luas ditandai dengan & \\
adanya kerak tanah pada batang pohon atau kerak tanah yang terbentuk dan menutup & 2 \\
batang pohon sekitar $1 / 2$ dari diameter batang & \\
$\begin{array}{l}\text { Terserang berat bagian pohon yang terserang relatif luas ditandai dengan adanya } \\
\text { kerak tanah pada batang pohon atau kerak tanah yang terbentuk sudah menutup }\end{array}$ & 3 \\
batang pohon & \\
$\begin{array}{l}\text { Mati kerak tanah pada batang pohon atau kerak tanah yang terbentuk sudah menutupi } \\
\text { seluruh batang pohon dan daun rontok serta tidak ada tanda-tanda kehidupan }\end{array}$ & 4 \\
\hline Sumber: Mardji (2003) &
\end{tabular}




\section{Analisis Data}

Analisa tingkat kerusakan

\section{a. Perhitungan kejadian serangan hama}

Penghitungan kejadian serangan hama dilakukan dengan menggunakan rumus oleh Tulung (2000):

$K=\frac{n}{N} X 100 \%$

Keterangan:

K: Kejadian serangan oleh rayap

$\mathrm{n}$ : Jumlah tanaman yang terserang oleh rayap

$\mathrm{N}$ : Jumlah tanaman dalam satu petak

b. Intensitas Serangan Tiap Petak Pengamatan

Intensitas serangan (I) dihitung dengan menggunakan rumus Mardji (2003) sebagai berikut:

Tabel 2. Cara Menentukan Kondisi Tanaman berdasarkan Intensitas Serangan (How to determine the condition of plants based on the intensity of the attack)

\begin{tabular}{ll}
\hline Intensitas serangan (\%) & Kondisi tanaman \\
\hline $0-1>$ & Tidak terserang (TT) \\
$1-25>$ & Rusak ringan (RR) \\
$25-50>$ & Rusak sedang (RS) \\
$50-75>$ & Rusak berat (RB) \\
$75-100$ & Rusak sangat berat / mati (RSB) \\
\hline
\end{tabular}

$I=\frac{X 1 Y 1+X 2 Y 2+X 3 Y 3+X 4 Y 4}{N . V} \times 100 \%$

dimana :

$\mathrm{I}$ : intensitas serangan $(\%)$

$\mathrm{N}$ : Jumlah tanaman yang diamati

$\mathrm{V}$ :Skor tertinggi yang diamati

$\mathrm{X}$ : jumlah pohon yang diamati

$\mathrm{X} 1$ : jumlah pohon yang terserang ringan (skor 1$)$

$\mathrm{X} 2$ : Jumlah pohon yang terserang sedang

(skor 2)

X3 : jumlah pohon yang terserang berat (skor 3)

$\mathrm{X} 4$ : jumlah pohon yang terserangsangat berat/mati (skor 4)

Y1: Pohon terserang ringan

Y2: Pohon terserang sedang

Y3: Pohon terserang berat

Y4: pohon terserang sangat berat/mati

\section{HASIL DAN PEMBAHASAN}

\section{Identifikasi Rayap}

Hasil penelitian di lokasi RKT 16/17 umur 3 tahun di HTI PT.Muara Sungai Landak (MSL) Kabupaten Mempawah dengan luas $922 \mathrm{Ha}$ di temukan 2 jenis rayap yaitu spesies Nasutitermes dan Coptotermes $s p$. Spesies ini banyak di temukan berjalan mencari makan (foraging) di atas tanah tanpa lubang kembara atau arboreal.Keberadaan jenis ini ditemukan karena berada di kawasan gambut yang di tanami pohon Acacia crassicarpa dan 
setengah panjang kepala dan tebal pada bagian dasar.

\section{Kejadian Serangan dan Intesitas Serangan}

Hasil pengamatan menyebutkan bahwa dari 46 petak, semua petak terserang oleh rayap dengan tingkat kejadian serangan yang terendah 2,94\% dan yang tertinggi $21,31 \%$. Semua petak terserang rata-rata dengan tingkat serangan ringan.

Suhu optimum rayap Nasutitermes longinasoides dan Coptotermes $s p$ untuk berkembang dan beraktivitas berkisar $15 \mathrm{C}-38 \mathrm{C}$ (Nandika et al. 2003). Kondisi ini sangat mendukung aktivitas rayap di bawah tegakan Acasia crassicarpa yang suhu dibawah tegakan 24 C- 31 C. Suhu ini termasuk kisaran suhu optimum yang diperlukan rayap untuk beraktivitas dan berkembang. Kelembaban optimum yang dibutuhkan rayap untuk berkembang dan beraktivitas adalah $75-90 \%$. Salah satu faktor yang mempengaruhi perilaku rayap adalah kelembaban. Kelembaban dapat mempengaruhi distribusi rayap (Pribadi, 2010).

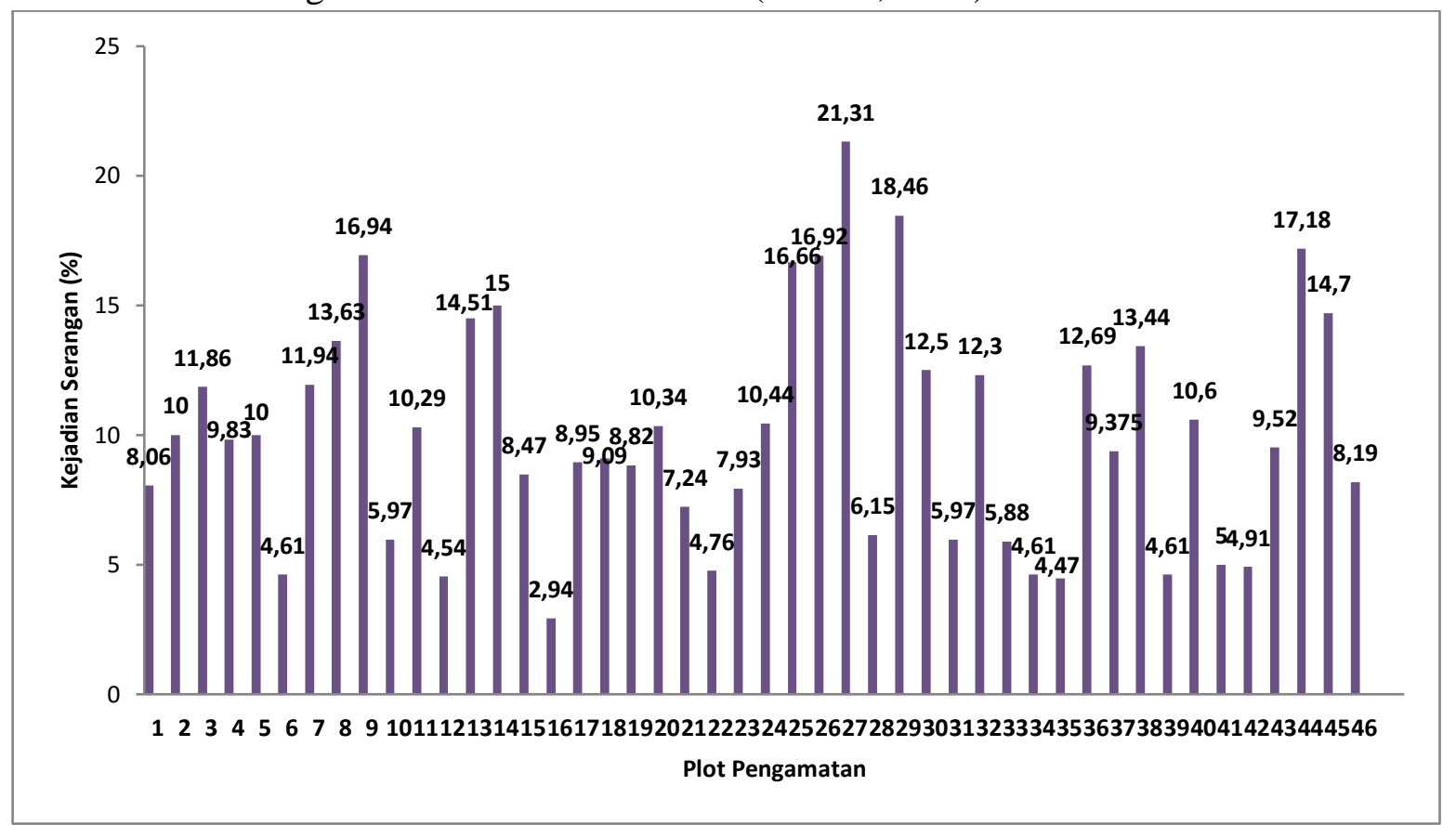

Gambar 1. Grafik Kejadian Serangan Rayap terhadap Tanaman Akasia (Acasia crassicarpa) di lahan HTI PT Muara Sungai Landak (Graph of the incidence of termite attack on acacia plants (acasia crassicarpa) in PT Muara Sungai Landak's HTI land)

Serangan rayap pada tanaman Acasia crassicarpa terjadi pada rata-rata diameter $635,46 \mathrm{~cm}$. Serangan rayap menyebabkan perbedaan terjadi pada diameter pohon., Menurut Mardji
(2003) dan Avry (2010) Serangan rayap bervariasi terdiri dari tidak terserang, terserang ringan, terserang sedang dan terserang berat. 


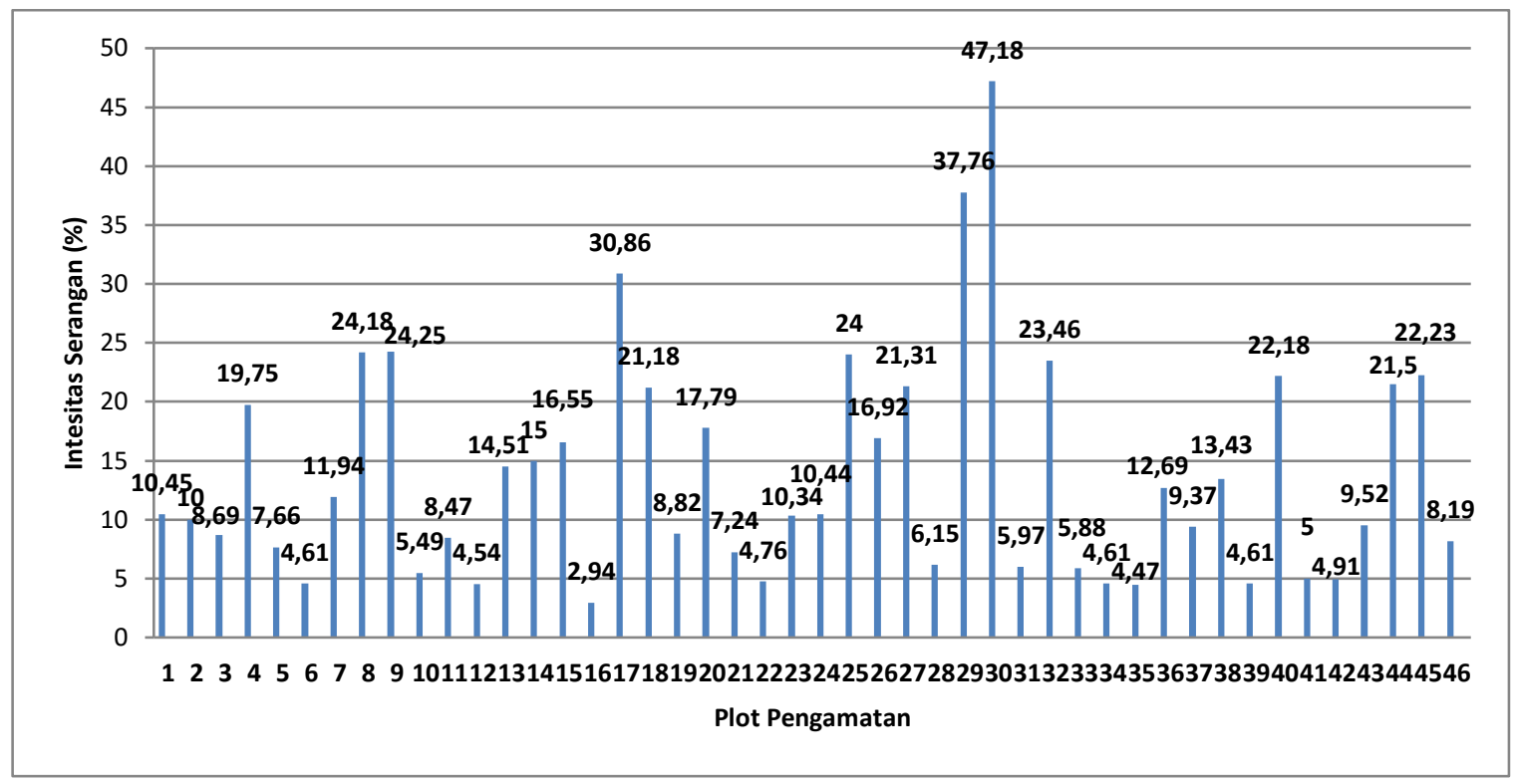

Gambar 2. Grafik Intesitas Serangan Rayap pada tanaman Akasia (Acasia crassicarpa) di lahan HTI PT Muara Sungai Landak. (Termite attack intensity graphic on acasia plants (acasia crassicarpa) in PT Muara Sungai Landak's HTI land)

Intesitas Serangan pada tanaman Acasia crassicarpa antara 2,94 - 47,18\% dengan rata-rata $13,73 \%$ dikategorikan kondisi tumbuhan rusak ringan. Terdapat 294 pohon yang terserang dari 2.944 pohon yang diamati, terdapat 260 pohon terserang ringan, 25 pohon terserang sedang, 9 pohon terserang berat. Berdasarkan kondisi tanaman berdasarkan kerusakan tanaman berdasarkan intensitas serangan pada 46 plot pengamatan adalah 43 plot rusak ringan dan 3 plot rusak sedang. Dengan rata-rata rusak ringan $0,93 \%$, rata-rata rusak sedang $0,06 \%$.

\section{KESIMPULAN}

Jenis rayap yang ditemui di lokasi penelitian pada tanaman Acasia crassicarpa di lahan HTI RKT 16/17 yaitu
Nasutitermes longinasoides dan Coptotermes sp.Tingkat kejadian serangan rayap terjadi pada 46 petak pengamatan di HTI PT Muara Sungai Landak memiliki tingkat kejadian sebesar 2,94\%-21,31\% dengan nilai rata-rata kejadian serangan sebesar 10,03\%.Tingkat intestas serangan rayap pada 46 petak pengamatan di HTI PT Muara Sungai Landak sebesar 2,94\% $47,18 \%$ dengan nilai rata-rata sebesar $13,73 \%$.

\section{DAFTAR PUSTAKA}

Amir, M. dan S. Kahono. 2003. Serangga Taman Nasional Gunung Halimun Jawa Bagian Barat. Biodiversity Conservation Project.

Habibi, Farah D, Sarma S. 2017. Keanekaragaman jenis rayap di kebun kelapa sawit PT. Bumi 
Pratama Khatulistiwa kecamatan Sungai Ambawang kabupaten Kubu Raya. Jurnal Hutan Lestari (2017). 5 (2) : 481-489

Mardji, D.2003. Identifikasi dan Penanggulangan Penyakit Pada Tanaman Kehutanan. Pelatihan Bidang Perlindungan Hutan di PT ITCI Kartika Utama, Samarinda.

Nandika D, Rismayadi Y, dan Fara D. 2003. Rayap: Biologi dan Pengendaliannya. Surakarta:
Universitas Muhammadiyah Surakarta Press.

Pribadi A. Pengaruh temperatur dan kelembaban terhadap tingkat kerusakan daun jabon (Anthocephalus Cadamba) Oleh Arthrochista Hilaralis. Jurnal Penelitian Hutan Tanaman. 8(1):17.

Untung, K. 1996. Pengantar Pengelolaan Hama Terpadu. Yogyakarta: Universitas Gajah Mada Press. 